Authority in developing the service. He would not be responsible for clinical performance, which should remain the responsibility of the medical profession.

\section{The role of the Health Authority}

In a number of hospitals it is quite obvious what is wrong and often what should be done about it. The experience of Normansfield illustrates this point very well. However, although the AHA is responsible for providing a service and can be held accountable for not doing so, it appears powerless to insist on remedy, having neither rewards nor sanctions to shape the work of medical staff. There is confusion between clinical responsibility, which is the consultant's alone, and service responsibility which is shared. The ability of the Health Authority to intervene in management and service issues needs to be more clearly defined. At present the hint of confrontation is enough to cause talk of litigation and defence organizations. It should be quite routine that consultants are called to account for the way they have used the resources given to them to provide a service. Only the Regional Medical Officer or the Area Medical Officer in AHA(T)s exercise the right to suspend consultants, and even then it has to be on grounds of obvious illness or extreme moral turpitude.

\section{Conclusion}

There is evidence that there is a gap between the responsibility of a Health Authority to provide a comprehensive service and the contractual obligation of consultants to do so. Where a full service is not provided, the senior clinical staff are blamed for not meeting a responsi- bility which has not in fact been delegated to them. The Health Authority is held accountable for services over which they have no direct control.

There are some measures which might improve the position which are offered for deliberation:

(1) An alteration in the consultant psychiatrist's contract to include the principle of corporate responsibility for comprehensive mental illness service.

(2) A separation of clinical responsibility from organizational responsibility (also included in revision of contract) to restore the chain of accountability in matters of organization while leaving clinical autonomy untouched.

(3) Much improved statistics and epidemiology, so that both clinician and Authority can monitor the outcome of agreed objectives and reach a comprehensive service through more informal means.

(4) The delegation of District responsibility for medical organization (but not clinical responsibility) to an appointed and accountable individual. $\mathbf{A}$ Chief of Service with a renewable appointment and some formal powers is preferable to the medical superintendent model.

(5) More formal ways for the Health Authority to hold psychiatrists accountable for the use of resources allocated to them.

(6) Good practice should be rewarded by public acknowledgement. Enhanced public reputation is a more powerful incentive for most doctors than private financial reward.

\title{
Clinical Psychologists and Psychiatrists Working Together in the Community
}

\author{
By Michael Frost, Clinical Psychologist, All Saints Hospital and ANDree LdDel, Principal Lecturer in Psychology,
} North East London Polytechnic

Since the publication of the Trethowan Report (1977) psychologists have been encouraged to expand their role outside the more orthodox psychiatric setting. As a small and steadily developing professional group, they have attempted to gain visibility by seeking alliances with medical specialties other than psychiatry, which had provided them with a kind of sheltered environment since the inception of the National Health Service. General practitioners have probably most often been solicited in these attempts to obtain a wider recognition. The favourable response of many general practitioners created the necessary climate to stimulate clinical psychologists to carry out systematic evaluations of their contribution to primary care (McPherson and Feldman, 1977; Johnston, 1978; Ives, 1979; Koch, 1979; Earll and Kincey, 1980).

On the other hand, similar evaluation of the contribution of clinical psychologists to psychiatry had not appeared essential. Historically, clinical psychology developed as a discipline alongside psychiatry to carry out standardised psychological assessments; subsequently, its functions were extended, notably in psychological therapies, and psychologists' posts proliferated. In addition to psychiatric hospitals, clinical psychologists were sited in academic departments of psychiatry, general and district hospitals and also other settings where psychiatrists were employed. This steady growth of these employment opportunities seems to indicate that their contribution has not been in question; so, in view of the gradual devolution of psychiatric provisions outside hospitals, it seems appropriate to reconsider the contribution of clinical psychologists. This discussion focuses on the relationship between a group of clinical psychologists and psychiatrists who are providing out-patient facilities in the same health district but practising independently of each other.

\section{Setting}

Newham Health District has no psychiatric hospital within its boundaries. Goodmayes, the former West Ham 
Mental Hospital is situated in another Health Area, and psychiatrists from that hospital conduct out-patient clinics in facilities provided in Newham general hospitals. The clinical psychologists, on the other hand, operate a teaching unit located in a health centre which functions without medical practitioners. The development of this unit and the conditions relating to its operation have been reported elsewhere (Hallam and Liddell, 1978), but it is worth noting that its establishment had been supported by the Goodmayes psychiatrists through the Newham Psychiatric Division.

In the first two years of operation, 121 patients had made contact with the Unit; of these, 91 ( 75 per cent) were referred by the psychiatrists. At the end of the period, 27 of these patients were either still in treatment or on the waiting list. The remaining 64 psychiatrically-referred patients who were no longer in contact with the Unit comprised the sample for a retrospective study (Frost, 1980). From this small sample a number of trends were identified which form the basis for further evaluation of the effectiveness of psychologists and psychiatrists working together in the community.

In the Unit, therapy is offered for a wide range of neurotic and interpersonal problems-problems of anxiety and stress, habit disorders, interpersonal problems, sexual and marital problems, and psychological adjustment to life events. The psychiatrists referred nearly half of their patients (48.4 per cent) with a presenting problem of anxiety and stress, including high levels of free floating anxiety, panic attacks, phobic and obsessive reactions, and psychosomatic symptoms; the remaining patients were referred for interpersonal, marital and sexual problems. No patient was referred for habit disorder or psychological adjustment to life events.

\section{Evaluation}

The Unit provided brief goal-directed therapy within a range of 10 to 30 sessions. The median number of treatment sessions was nine, and only four patients required more than 26 sessions. The Unit lost only 26 per cent of its treated patients before the sixth session.

Nineteen of the referred patients failed to attend for their first appointment. These patients were not significantly longer on the Unit's waiting list than those who did attend. However, there was a significantly longer delay between the last appointment with the referring psychiatrist and the first appointment at the Unit (82.9 days vs $\mathbf{5 6 . 1}$ days). Diagnosis was also related to attendance; more patients with anxiety/stress or marital/sexual problems came forward than those with interpersonal problems.

\section{Outcome}

Over a follow-up period of between three months and two years 80 per cent of the patients surveyed did not make additional demands upon the psychiatrists. Those patients who did return to see the psychiatrists were identified as those who had been known to them for a period of more than six months before their referral, had continued to attend the psychiatrists whilst on the Unit's waiting list, and were receiving medication.

\section{Conclusion}

In summary, a crucial factor in failure to attend the first appointment appeared to be the time patients were kept waiting before treatment, and it seems that patients with interpersonal problems were most at risk-a rather predictable finding. Less predictable was the lack of referrals for patients with habit disorders or problems with adjustment to life events. It may be that they are dealt with in this district by GPs who know how stretched local psychiatric provisions are.

It seems that psychiatrists were able to refer some of their patients to the clinical psychologists with some benefit, at least to themselves in terms of time saved. The fact that most referred patients did not return to them may be as much a reflection of careful selection as of the provision by the clinical psychologists of therapy which patients could accept and respond to.

Further prospective evaluations are needed to assess the interactions of psychiatrists and clinical psychologists, particularly where they are concurrently or sequentially treating the same patient; and to identify those patients most likely to benefit from referral to clinical psychologists.

\section{Acknowledgement:}

Thanks are due to Drs Abrahamson, Goldberg, Gordon, Slattery, Consultant Psychiatrists, Goodmayes Hospital, who have referred their patients and allowed their records to be studied.

\section{REFERENCES}

EARLL, L. \& KINCEY, J. (1980) A controlled trial evaluation of psychological intervention at the primary care level. Paper presented at the March 1980 British Psychological Conference at the University of Aberdeen.

Frost, M. (1980) A First Evaluation of an East End Community Psychology Clinic. Unpublished M.Sc. thesis, North East London Polytechnic.

Hallam, R. S. \& LDDell, A. (1978) A community clinic for teaching psychotherapy. Bulletin of the British Psychological Society, 31, 145-46.

IVEs, G. (1979) Psychological treatment in general practice. Journal of the Royal College of General Practitioners, 29, 343-51.

JoHNSTON, M. (1978) The work of a clinical psychologist in primary care. Journal of the Royal College of General Practitioners, 28, 661-67.

КосH, H. C. H. (1979) Evaluation of behaviour therapy intervention in general practice. Journal of the Royal College of General Practitioners, 29, 337-40.

McPherson, I. \& Feldman, M. P. (1977) A preliminary investigation of the role of the clinical psychologist in the primary care setting. Bulletin of the British Psychological Society, 31, 327-28.

Trethowan Commitree (1977) The Role of Psychologists in the Health Services. London: HMSO. 